\title{
Epitaxial Growth and Frictional Response of Otavite and Spherocobaltite on Dolomite (10.4) Surfaces Carlos Pimentel, ${ }^{\dagger, \ddagger}$ Enrico Gnecco, ${ }^{\S}$ and Carlos M. Pina ${ }^{*,+, \neq}$
}

\author{
†Departamento de Mineralogía y Petrología, Universidad Complutense de Madrid, E-28040 Madrid, Spain \\ FInstituto de Geociencias (UCM-CSIC), C/José Antonio Novais, 2, E-28040 Madrid, Spain ${ }^{\$}$
}

Otto Schott Institute of Materials Research, Friedrich Schiller University Jena, D-07742 Jena, Germany

\begin{abstract}
Growth of otavite $\left(\mathrm{CdCO}_{3}\right)$ and spherocobaltite $\left(\mathrm{CoCO}_{3}\right)$ has been promoted on dolomite (10.4) surfaces at room temperature by immersing cleaved dolomite crystals in highly supersaturated solutions with respect to those phases. In situ atomic force microscopy (AFM) observations show that otavite and spherocobaltite overgrow preferentially on dolomite step edges and (10.4) terraces by two-dimensional nucleation. High-resolution friction AFM images reveal the parallelism between the lattices of the overgrowths and the substrate, demonstrating that the growth of otavite and spherocobaltite on dolomite (10.4) surfaces is epitaxial. Similar values of lattice parameters measured on high-resolution friction images of substrates and overgrowths indicate the accommodation of the otavite and spherocobaltite (10.4) surface lattices to the dolomite substrate structure. The frictional response of otavite and spherocobaltite

overgrowth surfaces resulted to be significantly higher than that of dolomite. These differences in frictional response can be attributed to the strain generated by the misfits between dolomite substrates and the overgrowths.
\end{abstract}

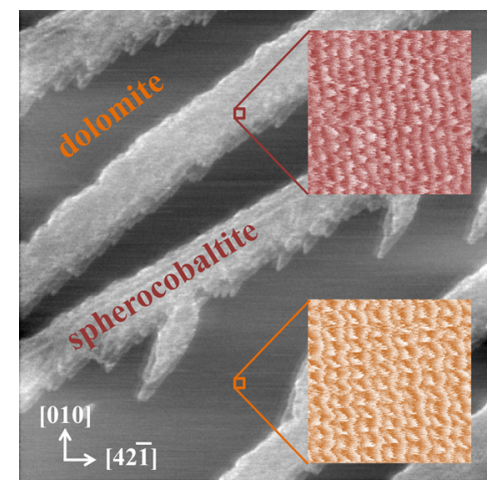

\section{INTRODUCTION}

Contamination of soil and natural water by heavy metals (e.g., $\mathrm{Cd}$, $\mathrm{Co}, \mathrm{Pb}, \mathrm{Hg}, \mathrm{Zn}$ ) has an increasing impact on the human society. These metals can produce severe health problems as they enter in the food chain. ${ }^{1}$ Particularly, cadmium and cadmium compounds have been defined by the International Agency for Research on Cancer as carcinogenic to humans, ${ }^{2}$ and cobalt, a trace element essential for life (i.e., vitamin $B_{12}$ ), has also been classified as potentially carcinogenic, despite insufficient evidence. ${ }^{3}$ Furthermore, cadmium and cobalt could produce other health problems, e.g., kidney damage, spontaneous abortions, and bone demineralization in the case of cadmium $^{4}$ and cardiomyopathy and reduction of pulmonary and spermatogenesis functions in the case of cobalt. ${ }^{5}$

A commonly proposed remediation method to reduce the amount of heavy metals in soil and water is their sequestration using minerals to uptake dissolved cations. ${ }^{6-8}$ Among the most common minerals, carbonates have been recognized as suitable natural materials to remove a number of pollutants from soil and natural and industrial waters. ${ }^{7,9-11}$ Thus, to better understand and control mineral-based removal mechanisms of inorganic and organic contaminants, it is essential to study the interactions at the nanoscale between polluted water and the surfaces of carbonate minerals. In particular, it is relevant (i) to determine minimum concentration levels in the aqueous solutions for the formation on pre-existing surfaces of both adsorbates and carbonate solid solutions containing metals, (ii) to identify the growth mechanism of newly formed layers (i.e., epitaxial/topotaxial or adsorption/absorption of molecules), and (iii) to evaluate the stability of contaminant-bearing layers grown on specific mineral surfaces.

To date, only a few experiments on the growth of cadmium and cobalt compounds on calcite and dolomite (10.4) surfaces have been reported. ${ }^{12-19}$ Although all of these publications have provided interesting information about the interactions between calcite and dolomite surfaces and metal-bearing aqueous solutions, more research is required to characterize the structure and stability of the overgrowths formed on those surfaces.

In this article, we present an atomic force microscopy (AFM) study of the growth of otavite $\left(\mathrm{CdCO}_{3}\right)$ a $\mathrm{n} \mathrm{d}$ spherocobaltite $\left(\mathrm{CoCO}_{3}\right)$ on dolomite (10.4) surfaces from aqueous solutions. The aim of this work is to investigate both the conditions under which cadmium- and cobalt-bearing overgrowths are formed on the dolomite (10.4) surface and the crystallochemical constraints of the growth process. We pay special attention to the influence of the lattice misfits between the overgrowths and the dolomite substrates on the growth mechanism. Moreover, we provide a novel character-ization of otavite and spherocobaltite overgrowths by an in situ measurement of their frictional response from the lateral force signal of the AFM. 
Table 1. Experiments Performed to Promote the Formation of Overgrowths of Otavite (Otav-) and Spherocobaltite (Spco-) ${ }^{a}$

\begin{tabular}{|c|c|c|c|c|c|c|c|c|}
\hline exp. & {$\left[\mathrm{Cd}^{2+}\right]$} & {$\left[\mathrm{Co}^{2+}\right]$} & {$\left[\mathrm{CO}_{3}{ }^{2-}\right]$} & $\left(\mathrm{Cd}^{2+}\right)$ & $\left(\mathrm{Co}^{2+}\right)$ & $\left(\mathrm{CO}_{3}{ }^{2-}\right)$ & $\mathrm{pH}_{\mathrm{C}}$ & $\beta$ \\
\hline otav- 100 & 0.033 & & 0.033 & 0.02557 & & 0.003134 & 9.36 & 100 \\
\hline otav- 150 & 0.038 & & 0.038 & 0.02881 & & 0.003953 & 9.41 & 145 \\
\hline otav- 200 & 0.043 & & 0.043 & 0.03188 & & 0.004806 & 9.44 & 195 \\
\hline otav- 250 & 0.048 & & 0.048 & 0.03486 & & 0.005701 & 9.47 & 251 \\
\hline otav- 300 & 0.053 & & 0.053 & 0.03775 & & 0.006633 & 9.50 & 316 \\
\hline otav- 400 & 0.058 & & 0.058 & 0.04057 & & 0.007597 & 9.52 & 389 \\
\hline otav- 450 & 0.063 & & 0.063 & 0.04333 & & 0.008589 & 9.55 & 468 \\
\hline otav- 500 & 0.065 & & 0.065 & 0.04412 & & 0.008979 & 9.55 & 501 \\
\hline otav- $900^{b}$ & 0.085 & & 0.085 & 0.05481 & & 0.01321 & 9.62 & 912 \\
\hline spco-70 & & 0.59 & 0.59 & & 0.1787 & 0.04162 & 9.36 & 71 \\
\hline spco-100 & & 0.73 & 0.73 & & 0.2072 & 0.05010 & 9.37 & 100 \\
\hline
\end{tabular}

${ }^{a}$ In square brackets are shown the concentrations of the ions in mmol/L. In round brackets are shown the ion activities. $\mathrm{pH}_{\mathrm{C}}$ is the calculated $\mathrm{pH}$, and $\beta$ is the supersaturation with respect to otavite or spherocobaltite. ${ }^{b}$ Solution only for SEM observations.

\section{MATERIALS AND METHODS}

2.1. Dolomite Sample Characterization. Crystals used in this work are of natural dolomite $\left(\mathrm{CaMg}\left(\mathrm{CO}_{3}\right)_{2}\right)$ from Eugui, Spain. These crystals were confirmed to be dolomite by X-ray powder diffraction using a Siemens D-500 diffractometer equipped with a $\mathrm{Cu}$ Ka source and chemical analyses performed with a scanning electron microscope (JEOL JSM- $640040 \mathrm{kV}$ ) equipped with an energy-dispersive X-ray (EDX) spectrometer (Link-analytical EDX system). All collected powder diffractograms fitted to the PDF-2 number 75-1710, which corresponds to natural dolomite (Figure S1, Supporting Information). EDX analyses are consistent with an almost stoichiometric natural dolomite with small amounts of $\mathrm{Mn}$ and Fe (Figure S2, Supporting Information).

2.2. Scanning Electron Microscopy (SEM) Observa-tions and EDX Analyses. Dolomite crystals were immersed in supersaturated solutions with respect to otavite or spherocobaltite (Table 1). These crystals were previously cleaved with a razor blade to obtain small rhombohedra showing faces with approximate areas of $20 \times 20 \mathrm{~mm}^{2}$. Then, they were placed in plastic vessels filled with $2 \mathrm{~mL}$ of the supersaturated solutions. Vessels were closed to avoid evaporation and kept at room temperature for $24 \mathrm{~h}$ to promote the formation of otavite overgrowths and up to 13 days for observing spherocobaltite overgrowths. Subsequently, crystals were removed from the vessels, dried at room temperature, and imaged with a scanning electron microscope (JEOL JSM-6400 $40 \mathrm{kV}$ ). The surfaces were chemically analyzed with an energy-dispersive X-ray spectrometer (Link-analytical EDX system).

2.3. In Situ AFM Crystal Growth Experiments. In situ experiments were conducted using an atomic force microscope (Nanoscope IIIA Multimode, Veeco Instruments) equipped with a $\sim 15 \times 15 \mu \mathrm{m}^{2}$ scanner and a closed fluid cell with an approximate volume of $100 \mu \mathrm{L}$. Topography, vertical deflection, and lateral deflection images were recorded with 512 lines per scan, scan rates ranging from 5 to $61 \mathrm{~Hz}$, and scan areas ranging from $10 \times$ $10 \mathrm{~nm}^{2}$ to $14 \times 14 \mu \mathrm{m}^{2}$. Silicon nitride AFM tips supported by triangular cantilevers with a nominal spring constant of $0.06 \mathrm{~N} / \mathrm{m}$ and a nominal tip radius of $2 \mathrm{~nm}$ (Bruker SNL-10D) were used. Dolomite crystals were cleaved along (10.4) faces with a razor blade just before placing them in the AFM fluid cell. Prior to each growth experiment, deionized water was injected to remove the impurities on dolomite surfaces and to adjust AFM parameters. Then, the growth of otavite and spherocobaltite was promoted on dolomite (10.4) surfaces by exposing them to supersaturated aqueous solutions with respect to these phases at room temperature (Table 1). Series of AFM images were recorded during the growth process and subsequently analyzed with software packages Nanoscope Analysis and WSxM. ${ }^{20}$ Lattice periodicities of substrates and overgrowths were estimated from two-dimensional (2D) fast Fourier transform maps calculated on high-resolution images using WSxM software..$^{20}$

2.4. Supersaturated Solutions. Solutions used to promote the formation of overgrowths on dolomite were prepared from reagentgrade $\mathrm{CdCl}_{2} \cdot 2.5 \mathrm{H}_{2} \mathrm{O}$ and $\mathrm{CoCl}_{2} \cdot 6 \mathrm{H}_{2} \mathrm{O}$ and $0.5 \mathrm{M}$ solution of $\mathrm{Na}_{2} \mathrm{CO}_{3}$ and using deionized water (Milli-Q, resistivity $18 \mathrm{M} \Omega \mathrm{cm}$ ). The supersaturations of the solutions with respect to otavite and spherocobaltite were calculated using the PHREEQC code for chemical speciation and the PHREEQC.dat database. ${ }^{21}$ The solubility product of spherocobaltite was taken from the Minteq.v4.dat database. ${ }^{21}$ Supersaturations were calculated with the following general expression

$$
\beta_{\text {overgrowth }}=\frac{a\left(\mathrm{M}^{2+}\right) \cdot a\left(\mathrm{CO}_{3}^{2-}\right)}{K_{\mathrm{sp}}}
$$

where $\mathrm{a}\left(\mathrm{M}^{2+}\right)$ are the activities of the cations $\left(\mathrm{Cd}^{2+}\right.$ or $\left.\mathrm{Co}^{2+}\right), \mathrm{a}\left(\mathrm{CO}_{3}{ }^{2-}\right)$ is the activity of the $\mathrm{CO}_{3}{ }^{2-}$ anion, and $\mathrm{K}_{\mathrm{sp}}$ is the solubility product of

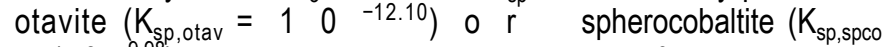
$=10^{-9.98}$ ). To calculate the super-saturations of both otavite and spherocobaltite, PHREEQC was run as a closed system. Table 1 shows the composition and supersaturations of the solutions, with respect to otavite and spherocobaltite, used in the experiments at 25 ${ }^{\circ} \mathrm{C}$.

2.5. Nanotribological Measurements. Frictional re-sponse of the surfaces was measured by recording lateral deflection images during increasing-decreasing cycles of normal forces between the AFM tip and the samples. The sizes of the images recorded during these measurements were about $250 \times 250 \mathrm{~nm}^{2}$, corresponding to about 150000 surface unit cells. The equation used to estimate the normal force was ${ }^{22}$

$$
F_{\mathrm{N}}=S k_{\mathrm{N}} V_{\mathrm{N}}
$$

where $k_{N}$ is the normal spring constant $\left(k_{N}=0.06 \mathrm{~N} / \mathrm{m}\right), S$ is the sensitivity of the photodetector (calculated from forcedistance curves recorded for each experiment), and $V_{N}$ is the set point value (in volts). 

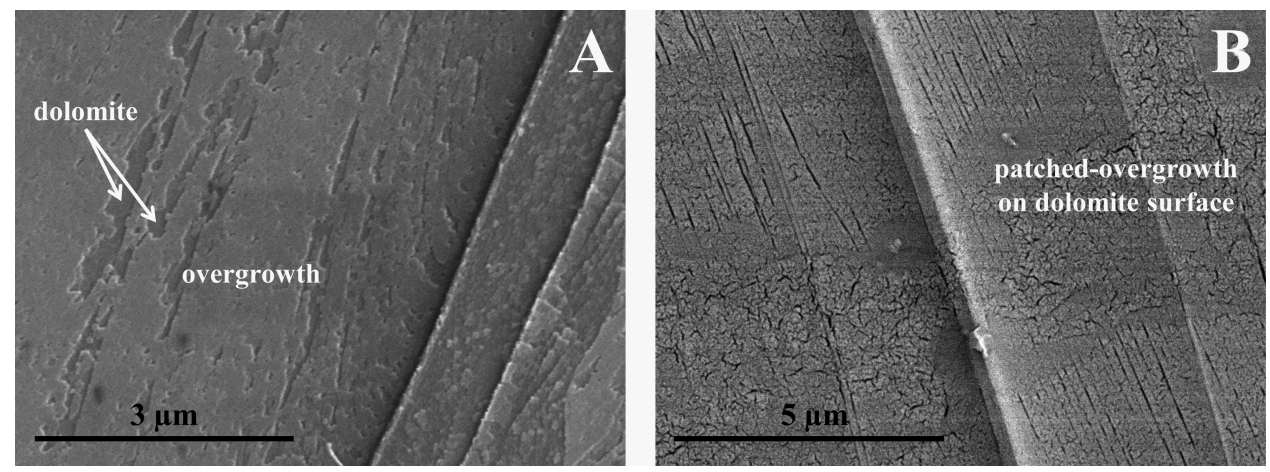

Figure 1. SEM images of (A) overgrowth on the dolomite (10.4) surface after $24 \mathrm{~h}$ of reaction with a solution highly supersaturated with respect to otavite $\left(\beta_{\text {otav }}=900\right)$ and $(\mathrm{B})$ overgrowth on the dolomite (10.4) surface after 13 days of reaction with a solution highly supersaturated with respect to spherocobaltite $\left(\beta_{\text {spco }}=100\right)$.

To calculate the lateral forces, the following equation was used $^{22}$

$$
F_{\mathrm{L}}=\frac{3 H}{2 L} k_{\mathrm{T}} S V_{\mathrm{L}}
$$

where $\mathrm{H}$ is the sum of half of the cantilever thickness and the tip height $(H=5.3 \mu \mathrm{m}), L$ is the length of the cantilever $(L=205 \mu \mathrm{m})$, $\mathrm{k}_{\mathrm{T}}$ is the torsional spring constant of the cantilever $\left(\mathrm{k}_{\mathrm{T}}=47.02 \mathrm{~N} /\right.$ $\mathrm{m}$ ), and $\mathrm{V}_{\mathrm{L}}$ is the difference of the averaged trace and retrace signals divided by 2 . The parameter $k_{T}$ was estimated from $k_{N}$ and the cantilever geometry using the formula proposed by Noy et al. ${ }^{23}$

$$
k_{\mathrm{T}}=\frac{2}{\left[6 \cos ^{2} \theta+3(1+v) \sin ^{2} \theta\right]}\left(\frac{L}{h}\right)^{2} k_{\mathrm{N}}
$$

where $\theta$ is the angle of the triangular cantilever $\left(60^{\circ}\right.$ for the tips used), $v$ is the Poisson ratio for the silicon nitride tips (0.24), and $h$ is the height of the tip $(5 \mu \mathrm{m})$.

\section{RESULTS AND DISCUSSION}

3.1. SEM Observations. Dolomite (10.4) surfaces exposed to $\mathrm{Cd}$-bearing solutions with a supersaturation with respect to otavite $\left(\beta_{\text {otav }}=900\right)$ are coated after $24 \mathrm{~h}$ of reaction with an almost homogeneous thin layer (Figure 1A). In the experi-ments conducted using $\mathrm{Cd}$-bearing solutions with super-saturations lower than $\beta_{\text {otav }}=900$, the formation of such a layer was not observed with SEM. Differently, overgrowth formation on dolomite surfaces from Co-bearing solutions was only detected when solutions with supersaturations for spheroco-baltite $\beta_{\mathrm{spco}}=100$ were used, and only after reaction times longer than $48 \mathrm{~h}$, a thin patched layer is deposited (Figure 1B). For supersaturations with respect to spherocobaltite higher than $\beta_{\text {spco }}=100$, almost instantaneous homogeneous nucleation occurs in the bulk of the solutions, precluding a clear observation of epitaxial growth of spherocobaltite on dolomite. Such a nucleation is detected by a greenish turbidity, which masks the formation of overgrowths on the surfaces.

Because the observed overgrowth formation on the dolomite (10.4) surface consisted in the deposition of a few monolayers (a few nanometers in thickness), partially carpeting the surfaces, EDX analyses of the overgrowths are affected by the composition of the dolomite substrate. Therefore, considering that the EDX detection depth is $\sim 2 \mu \mathrm{m}$, such analyses did not allow us to quantify the $\mathrm{Cd}$ and $\mathrm{Co}$ content, which remained below the detection limit of this technique ( $2 \mathrm{ppm})$.
3.2. In Situ AFM Crystal Growth Experiments. 3.2.1. Otavite Growth on Dolomite (10.4) Surface. In AFM experiments, the formation of overgrowths started just after the first injection of the Cd-bearing solutions in the AFM fluid cell (see experiments labeled as Otav- in Table 1). Lateral force images were recorded while scanning almost parallel to the [42.1] direction on the (10.4) dolomite faces. A series of consecutive images show that overgrowths form by $2 \mathrm{D}$ nucleation on dolomite (10.4) terraces and cleavage step edges, in agreement with observations previously reported by Callagon et al. ${ }^{18}$ Once nucleated, 2D islands spread to cover almost all of the surface (Figure 2A). Highresolution friction images taken on both the dolomite substrate and the overgrowths showed that the lattices of both phases are almost identical and parallel (Figure 2B,C). This demonstrates that the newly formed phase is otavite and it grows epitaxially on the dolomite (10.4) surface. Periodicities of the surface lattice of dolomite, as estimated on the high-resolution images (Figures 2B and S3, Supporting Information), are about $0.50 \mathrm{~nm}$ for the [01.0] direction and $0.83 \mathrm{~nm}$ for the [42.1] direction, i.e., slightly larger than those calculated from the dolomite bulk structure using TEM and X-ray diffraction analyses: $0.481 \mathrm{~nm}$ for the [01.0] direction and $0.771 \mathrm{~nm}$ for the [42.1] direction. ${ }^{24}$ This small discrepancy, which can be attributed to calibration issues, does not affect the relative misfit as subsequently calculated using eq 5 . The periodicities estimated on the otavite overgrowths in a similar way along the [01.0] and [42.1] directions are 0.48 and $0.82 \mathrm{~nm}$, respectively (Figures $2 \mathrm{C}$ and S4, Supporting Information). These values are very close to those measured on dolomite.

The observation of overgrowth formation of otavite on dolomite differs from the previously reported observations of otavite growing on calcite surfaces. ${ }^{13,16}$ Whereas otavite 2D islands do not show any preferentially orientation with respect to the dolomite substrate, on calcite, they are elongated along the [42.1] direction. $^{13,16}$ Furthermore, the step decoration observed on dolomite substrates (Figure $2 \mathrm{~A}$ and observations reported by Callagon et al. ${ }^{18}$ ) was not detected on calcite substrates.

3.2.2. Spherocobaltite Growth on Dolomite (10.4) Sur-face. The formation of overgrowths from Co-bearing solutions on dolomite surfaces occurs by an almost instantaneous nucleation on the step edges (see experiments labeled as Spcoin Table 1; Figure 3A). Only a few 2D islands form on the terraces, probably due to the presence of point defects or impurities located on the surfaces. As can be seen in Figure 3A, 

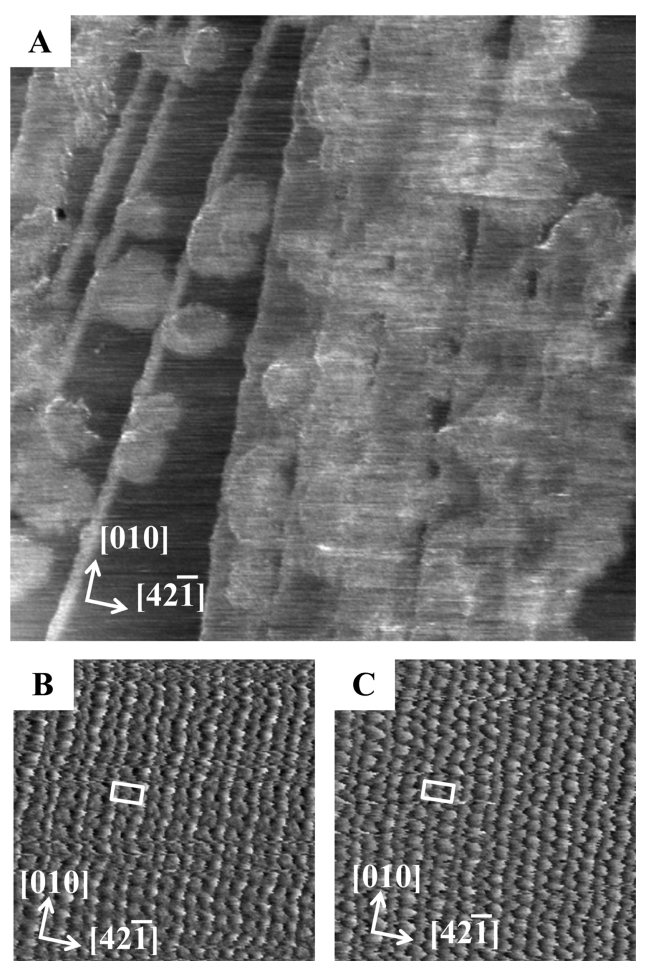

Figure 2. (A) AFM lateral force image $\left(1.6 \times 1.6 \mu \mathrm{m}^{2}\right)$ of epitaxial growth of otavite on the (10.4) dolomite surface immersed in a supersaturated solution (experiment Otav-400 in Table 1). Dark gray areas correspond to the dolomite substrate, and bright gray areas are the otavite 2D islands (about three monolayers $\sim 0.9 \mathrm{~nm}$ in thickness). High-resolution friction images of (B) dolomite substrate and $(C)$ otavite overgrowth $\left(9 \times 9 \mathrm{~nm}^{2}\right)$. White rectangles show the unit cells on the (10.4) surfaces.

$2 \mathrm{D}$ islands grow preferentially along the [48.1] direction of the dolomite substrate. High-resolution images recorded on the overgrowth and on the dolomite substrate clearly showed the parallelism between the lattices of both phases (Figure 3B,C). This demonstrates that the new phase formed from Co-bearing solutions is spherocobaltite and its growth on the dolomite (10.4) surface is epitaxial. Our observations of spherocobaltite growing on dolomite surfaces contrast with the previously reported formation of an amorphous Co-bearing hydroxy-carbonate phase on calcite (10.4) surfaces. ${ }^{16}$ The formation of different phases on dolomite and calcite (10.4) surfaces from Co-bearing solutions can be due to both the different supersaturations with respect to the spherocobaltite in the solutions and the different substrates used. As in the case of otavite, spherocobaltite lattice parameters were estimated on the high-resolution images (Figures $3 \mathrm{C}$ and S5, Supporting Information). These parameters $(0.50 \mathrm{~nm}$ for the [01.0] direction and $0.83 \mathrm{~nm}$ for the [42.1] direction) are essentially coincident (within the error bar) with those measured on dolomite.

3.2.3. Crystallographic Features of the Dolomite (10.4) Substrate and Overgrowths. As described before, ${ }^{25,26}$ the dolomite (10.4) lattice is defined by a rectangular unit cell with four friction maxima situated at its corners and one friction maximum situated within it (Figures $2 \mathrm{~B}$ and $3 \mathrm{~B}$ ). As can be seen in Figures $2 \mathrm{C}$ and $3 \mathrm{C}$, an identical pattern of friction maxima defines otavite and spherocobaltite (10.4) lattices. In all of the cases, friction maxima can be attributed to the interaction of the AFM tip with the oxygens of carbonate
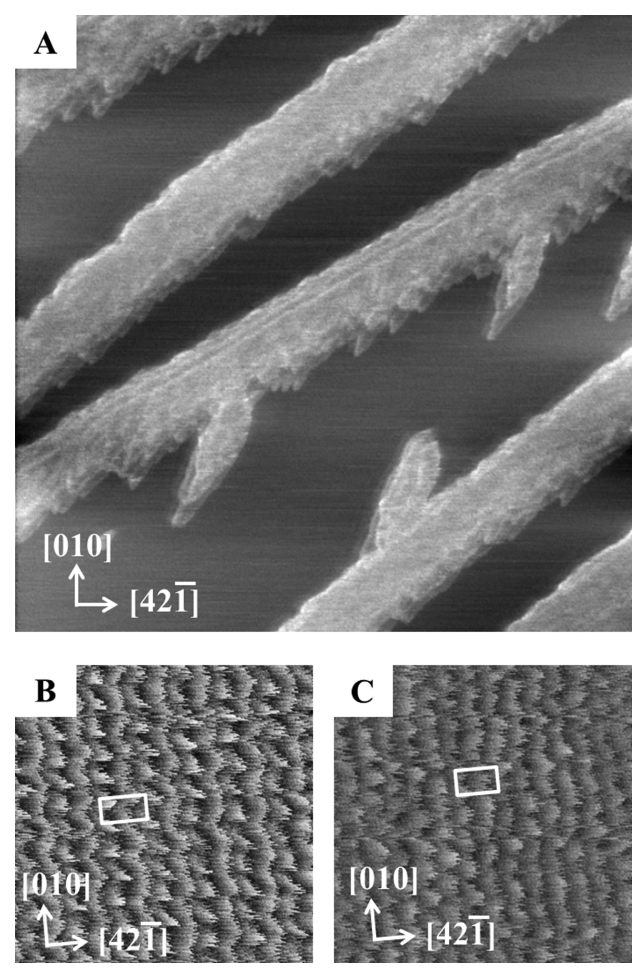

Figure 3. (A) AFM lateral force image $\left(2.0 \times 2.0 \mu \mathrm{m}^{2}\right)$ of epitaxial growth of spherocobaltite growing on the dolomite (10.4) surface immersed in a supersaturated solution (experiment Spco-100 in Table 1). Dark gray areas correspond to the dolomite substrate, and bright gray areas are the spherocobaltite overgrowth (about five monolayers $\sim 1.5 \mathrm{~nm}$ in thickness). High-resolution friction images of (B) dolomite substrate and (C) spherocobaltite overgrowth $\left(6 \times 6 \mathrm{~nm}^{2}\right)$. White rectangles show the unit cells on the (10.4) surfaces.

groups protruding from the (10.4) planes (Figure 4). These atoms act as pinning centers when the AFM tip slides over the crystal surface, which results in a characteristic stick-slip motion (Figure 5).

To evaluate the crystallographic constraints of the epitaxial growth of otavite and spherocobaltite on the dolomite (10.4) surface, it is of interest to analyze in detail the misfits between the dolomite and overgrowths lattices. Lattice misfits can be calculated using the equation

$$
\delta_{[u w w]}^{(10.4)}=\frac{L_{\mathrm{dol}}-L_{\mathrm{ota} / \mathrm{spco}}}{L_{\mathrm{otav} / \mathrm{spco}}} \times 100
$$

where $\delta_{[u w w}{ }^{(10.4)}$ is the misfit along a particular [uvw] crystallographic direction, $L_{\text {dol }}$ is the dolomite periodicity, and $L_{\text {otav/spco }}$ is the otavite or spherocobaltite periodicity along such a [uvw] direction. The [uvw] directions on the (10.4) surfaces considered are [01.0] and [42.1].

Table 2 shows the misfits of otavite-dolomite and spherocobaltite-dolomite epitaxial pairs, calculated using the (10.4) surface lattice parameters derived from bulk structures. As can be seen in Table 2, misfits are negative for the otavitedolomite epitaxial pair and positive for the spherocobaltitedolomite epitaxial pair. This indicates that whereas the epitaxial growth of otavite on the dolomite (10.4) surface should result in a contraction of the overgrowth lattice, the spherocobaltite formation on the dolomite (10.4) surface should imply a relaxation of the overgrowth lattice. This hypothesis is fully confirmed by our measurements. As already noticed in 

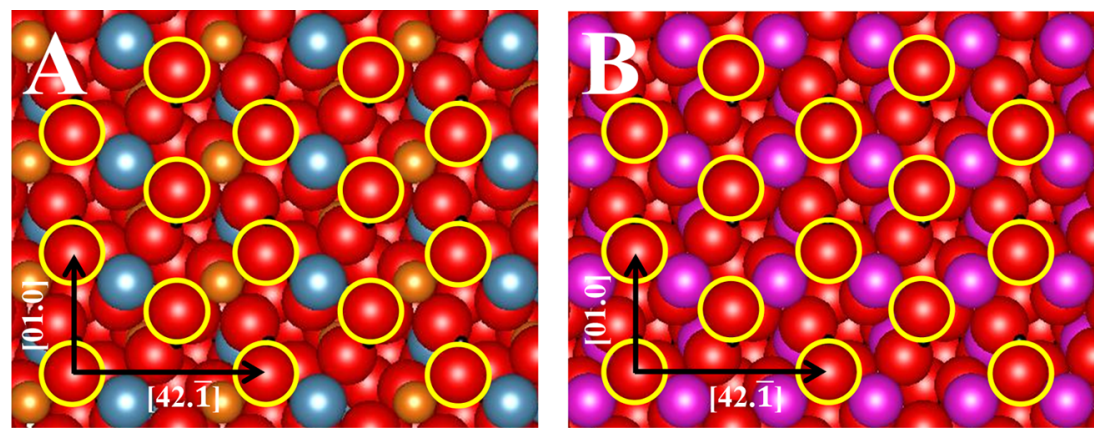

Figure 4. Structural schemes of the (10.4) cleavage surfaces of (A) dolomite and (B) otavite and spherocobaltite. Oxygen atoms are represented by red spheres, carbon atoms are represented by black spheres, calcium atoms are shown in blue, magnesium atoms are shown in orange, and cadmium/cobalt atoms are shown in magenta. Oxygen atoms enhanced by yellow rims are protruding from the surface. The interaction of these protruding oxygens with the AFM tip generates the maxima of friction observed in Figures $2 \mathrm{~B}, \mathrm{C}$ and $3 \mathrm{~B}, \mathrm{C}$. Dolomite, otavite, and spherocobaltite structural schemes were constructed using VESTA software. ${ }^{27}$

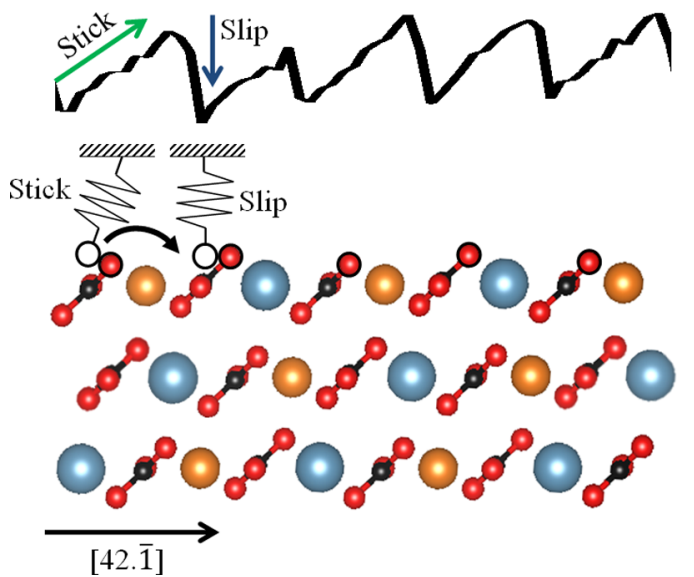

Figure 5. Dolomite structural scheme perpendicular to the (10.4) surface. Atoms are represented in different colors: oxygen in red, carbon in black, calcium in blue, and magnesium in orange. The black rim in red atoms represents the oxygen atoms protruding from the dolomite (10.4) surface. The black profile is a cross section taken on a dolomite high-resolution image showing the characteristic saw-tooth pattern of the stick-slip phenomena. The scheme was constructed using VESTA software. ${ }^{27}$

Sections 3.2.1 and 3.2.2, the lattice parameters of both otavite -dolomite and spherocobaltite-dolomite epitaxial pairs, as estimated from the high-resolution lateral force images, are almost identical. This gives strong evidence that the otavite and spherocobaltite surface lattices are shrunk and stretched, respectively, to fit the dolomite substrate perfectly.

The misfits between the overgrowths and the substrates can also explain the different formation behavior observed in the otavite/dolomite and otavite/calcite systems and in the spherocobaltite/dolomite and spherocobaltite/calcite systems. As explained above, when otavite grows on calcite, it shows a preferential orientation along the [42.1] direction, ${ }^{13,16}$ whereas on dolomite, otavite does not have any preferential orientation. Growing on calcite, the otavite structure has to expand to accommodate the deformation, leading to misfits of $1.42 \%$ and $3.05 \%$ for the [01.0] and [42.1] directions, respectively. The almost isotropic growth of otavite on dolomite surfaces could be explained by the closeness of the misfits along both directions, [01.0] and [42.1] ( $-2.24 \%$ and $-1.92 \%$, respectively).

Spherocobaltite grows on dolomite surfaces but not on calcite substrates in contact with Co solutions. Instead, an amorphous Co-bearing hydroxy-carbonate phase is formed. ${ }^{16}$ In this case, the inhibition of spherocobaltite formation could be related to the high misfits between spherocobaltite and calcite when parameters from bulk structure are used (7.08\%for the [01.0] direction and $10.35 \%$ for the [42.1] direction), which are almost 2 times larger than those calculated for the spherocobaltite-dolomite pair used (3.24\% for the [01.0] direction and 5.11\% for the [42.1] direction).

3.2.4. Nanotribological Behavior of Overgrowths. Regard-less of the relaxation or contraction of overgrowths on dolomite (10.4) surfaces, a distinct nanotribological response has been recorded. The average lateral forces were measured on both dolomite substrates and otavite and spherocobaltite overgrowths by scanning the AFM tip back and forth at increasing and decreasing values of the normal force $F_{N}$ applied on the surfaces. Variations of lateral forces, $F_{L}$, for increasing $F_{N}$ are shown in Figure $6 A, B$. In the applied range of values, no wear was observed while scanning, either on the dolomite substrate or on otavite and spherocobaltite overgrowths. Friction coefficients $\left(\mu=d F_{L} / d F_{N}\right)$ for the substrate and the overgrowths can be obtained from linear regression of data shown in Figure $6 \mathrm{~A}, \mathrm{~B}$. As a result, we obtained $\mu_{\text {otav }}=0.44$ and $\mu_{\text {spco }}=0.36$ for otavite and spherocobaltite, respectively. Both friction coefficients are about 3 times larger than those of the

Table 2. Lattice Parameters from Bulk Structures of Otavite, Spherocobaltite, Calcite, and Dolomite (10.4) Surfaces and Calculated Lattice Misfits between Overgrowths (Otavite and Spherocobaltite) and Substrates (Calcite and Dolomite)

\begin{tabular}{|c|c|c|c|c|c|c|}
\hline \multirow[b]{2}{*}{ phase } & \multirow[b]{2}{*}[01.0]{$(\mathrm{nm})$} & \multirow[b]{2}{*}[42.\overline{1}]{$(\mathrm{nm})$} & \multicolumn{2}{|c|}{ calcite substrate $^{28}$} & \multicolumn{2}{|c|}{ dolomite substrate ${ }^{24}$} \\
\hline & & & $\delta_{[01.0]}^{(10.4)(\%)}$ & $\delta_{[42.1]}^{(10.4)}(\%)$ & $\delta_{[01.0]}^{(10.4)}(\%)$ & $\delta_{[42.1}^{(10.4)}(\%)$ \\
\hline otavite $^{29}$ & 0.492 & 0.786 & 1.42 & 3.05 & -2.24 & -1.92 \\
\hline spherocobaltite $^{29}$ & 0.466 & 0.734 & 7.08 & 10.35 & 3.24 & 5.11 \\
\hline calcite $^{28}$ & 0.499 & 0.810 & & & & \\
\hline dolomite $^{24}$ & 0.481 & 0.771 & & & & \\
\hline
\end{tabular}



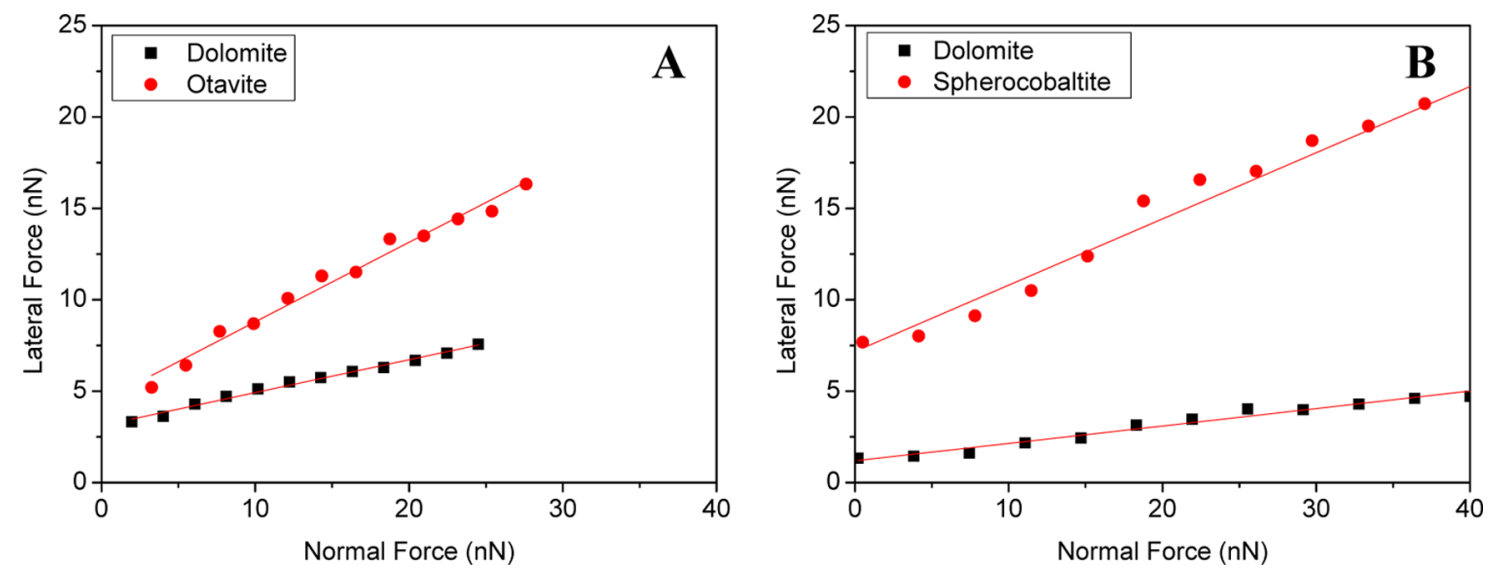

Figure 6. Lateral force vs normal force plot of (A) otavite on dolomite and (B) spherocobaltite on dolomite. Lateral forces were measured along the $[42 . \overline{1}]$ directions. Red lines show the linear regression used to calculate the friction coefficients. In all of the cases, values for the regression coefficient $R^{2}$ are higher than 0.97 .

dolomite substrates on which the overgrowths formed $\left(\mu_{\mathrm{dol}}=0.18\right.$ and 0.10 , respectively). Because substrates used in these experiments were obtained from the same dolomite crystal, identical nanotribological response can be expected. Therefore, differences in friction coefficients for dolomite must be related to deviations from nominal cantilever and AFM tip values provided by the manufacturer (i.e., tip radius, normal spring constant, and cantilever dimensions). Nevertheless, it appears that such deviations from nominal values have scarce relevance in the overgrowths versus substrate friction coefficient ratios.

For comparison, the frictional response of otavite on the calcite (10.4) substrate was previously measured using AFM by Cubillas and Higgins. ${ }^{14}$ According to the authors, the friction behavior of otavite and calcite is similar. Whereas for normal forces lower than $40 \mathrm{nN}$, calcite lateral force values are slightly higher than those for otavite, for normal forces above $40 \mathrm{nN}$, otavite showed faintly higher lateral force values. Differently, in our experiments, we have always observed a much higher frictional signal on otavite than on dolomite. The differences between the nanotribological response of otavite growing on dolomite and on calcite (10.4) surfaces might be related to the different modifications of the lattice parameters when otavite layers accommodate to the dolomite and calcite substrates. Similarly, the relatively high friction values of spherocobaltite reported here for the first time could be also attributed to the accommodation of the spherocobaltite lattice to the dolomite substrate. However, it is difficult to conclude if any other tip- surface interactions can also influence the nanotribological response of the surfaces of otavite, spherocobaltite, dolomite, and calcite. Differences between dolomite and calcite nano-tribological behavior can also be related to the ions picked up by the AFM silicon nitride tip while scanning in contact mode and to different relaxations of the tip apex so covered. $^{26}$ A complete explanation of the differences on the nanotribological behavior of these mineral surfaces is beyond the scope of this article, and it would require molecular dynamics simulations also to quantify the influence of other effects on the AFM tip- surface frictional response, such as the formation of hydration layers. $^{30,31}$

\section{CONCLUSIONS}

In summary, growth of otavite and spherocobaltite on the dolomite (10.4) surface can be promoted at room temperature using aqueous solutions highly supersaturated with respect to

those phases. The overgrowths formed by $2 \mathrm{D}$ nucleation on step edges and terraces of dolomite (10.4) surfaces. Highresolution AFM friction images showed that both phases grow epitaxially on dolomite (10.4) surfaces, with the lattices of the overgrowths and the dolomite (10.4) substrates being parallel.

Lattice measurements performed on high-resolution AFM friction images of otavite and spherocobaltite overgrowths demonstrate that the structures of these minerals accom-modate to the dolomite (10.4) lattice. Due to the misfits between the lattice parameters of otavite and spherocobaltite and those of the dolomite (10.4) surface, structural strains are expected. Such a structural strain might be partially responsible for the higher frictional responses of the overgrowths compared to those of dolomite surfaces.

\section{ACKNOWLEDGMENTS}

This work was partially supported by the Spanish Government (projects MAT2012-38810 and CGL2013-48247-P). AFM and SEM observations were carried out at ICTS Centro Nacional de Microscopı a Electrónica, Madrid. Authors thank Prof. Steve Parker for his insightful comments at Goldschmidt Conference in Prague (2015). C.P. is thankful to the Spanish Ministry of Education, Culture and Sports for an FPU Grant. 


\section{REFERENCES}

(1) Singh, B. R.; Steinnes, E. Soil and Water Contamination by Heavy Metals. In Soil Processes and Water Quality; Stewart, B. A., Ed.; CRC Press, 1994; pp 233-271.

(2) IARC. Cadmium and Cadmium Compounds. Arsenic, Metals, Fibres, and Dusts; IARC Monographs; IARC, 2009; Vol. 100, pp 121146.

(3) IARC. Cobalt and Cobalt Compounds. Chlorinated Drinking-Water; Chlorination By-Products; Some Other Halogenated Compounds; Cobalt and Cobalt Compounds; IARC Monographs; IARC, 1991; Vol. 52, pp 363 -462 .

(4) Godt, J.; Scheidig, F.; Grosse-Siestrup, C.; Esche, V.; Brandenburg, P.; Reich, A.; Groneberg, D. A. The toxicity of cadmium and resulting hazards for human health. J. Occup. Med. Toxicol. 2006, 1, 22

(5) Donaldson, J. D.; Beyersmann, D. Cobalt and Cobalt Compounds. Ullmann's Encyclopedia of Industrial Chemistry; Wiley, 2005; Vol. 9, pp 429-465.

(6) Chen, X.; Wright, J. V.; Conca, J. L.; Peurrung, L. M. Evaluation of heavy metal remediation using mineral apatite. Water, Air, Soil Pollut. 1997, 98, 57 -78

(7) Lee, M.; Paik, I. S.; Kim, I.; Kang, H.; Lee, S. Remediation of heavy metal contaminated groundwater originated from abandoned mine using lime and calcium carbonate. J. Hazard. Mater. 2007, 144, 208-214.

(8) Simeonidis, K.; Kaprara, E.; Samaras, T.; Angelakeris, M.; Pliatsikas, N.; Vourlias, G.; Mitrakas, M.; Andritsos, N. Optimizing magnetic nanoparticles for drinking water technology: The case of $\mathrm{Cr}(\mathrm{VI})$. Sci. Total Environ. 2015, 535, 61 -68

(9) Prieto, M. Thermodynamics of solid solution-aqueous solution systems. Rev. Mineral. Geochem. 2009, 70, 47 -85

(10) Ok, Y. S.; Lim, J. E.; Moon, D. H. Stabilization of Pb and Cd contaminated soils and soil quality improvements using waste oyster shells. Environ. Geochem. Health 2011, 33, 8 3 -91.

(11) Agwaramgbo, L.; Magee, N.; Nunez, S.; Mitt, K. Biosorption and chemical precipitation of lead using biomaterials, molecular sieves, and chlorides, carbonates, and sulfates of $\mathrm{Na} \& \mathrm{Ca}$. J. Environ. Prot. 2013, 04 1251-1257.

(12) Chiarello, R. P.; Sturchio, N. C. Epitaxial growth of otavite on calcite observed in situ by synchrotron X-ray scattering. Geochim. Cosmochim. Acta 1994, 58, 5633-5638.

(13) Pérez-Garrido, C.; Fernández-Díaz, L.; Pina, C. M.; Prieto, M. In situ AFM observations of the interaction between calcite (1014) surfaces and Cd-bearing aqueous solutions. Surf. Sci. 2007, 601, 5499-5509.

(14) Cubillas, P.; Higgins, S. R. Friction characteristics of Cd-rich carbonate films on calcite surfaces: implications for compositional differentiation at the nanometer scale. Geochem. Trans. 2009, 10, 7 .

(15) Xu, M.; Kovarik, L.; Arey, B. W.; Felmy, A. R.; Rosso, K. M.; Kerisit, $S$. Kinetics and mechanisms of cadmium carbonate heteroepitaxial growth at the calcite (1014) surface. Geochim. Cosmochim. Acta 2014 134, 221-233.

(16) Xu, M.; Ilton, E. S.; Engelhard, M. H.; Qafoku, O.; Felmy, A. R.; Rosso, K. M.; Kerisit, S. Heterogeneous growth of cadmium and cobal carbonate phases at the (1014) calcite surface. Chem. Geol. 2015, 397, $24-36$.

(17) Riechers, S. L.; Rosso, K. M.; Kerisit, S. N. Nucleation and EpitaxyMediated Phase Transformation of a precursor cadmium carbonate phase at the calcite/water interface. J. Phys. Chem. C 2017, 121, 5012-5019.

(18) Callagon, E. B. R.; Lee, S. S.; Eng, P. J.; Laanait, N.; Sturchio, N. C.; Nagy, K. L.; Fenter, P. Heteroepitaxial growth of cadmium carbonate at dolomite and calcite surfaces: mechanisms and rates. Geochim. Cosmochim. Acta 2017, 205, 360-380.

(19) Riechers, S. L.; Kerisit, S. N. Anisotropic growth of otavite on calcite: implications for heteroepitaxial growth mechanisms. Cryst. Growth Des. 2018, 18, 159-170.

(20) Horcas, I.; Fernández, R.; Gómez-Rodríguez, J. M.; Colchero, J.; Gómez-Herrero, J.; Baro, A. M. WSXM: A software for scanning probe microscopy and a tool for nanotechnology. Rev. Sci. Instrum. 2007, 78, No. 013705.

(21) Parkhurst, D. L.; Appelo, C. A. J. Description of Input and Examples for PHREEQC Version 3-A Computer Program for Speciation, Batch-Reaction, One-Dimensional Transport, and Inverse Geochemical Calculations; U.S. Geological Survey Techniques and Methods; USGS, 2013; Book 6, Chapter A43, 497 p.

(22) Lüthi, R.; Meyer, E.; Haefke, H.; Howald, L.; Gutmannsbauer, W.; Guggisberg, M.; Bammerlin, M.; Güntherodt, H.-J. Nano-tribology: An UHV-SFM study on thin films of $\mathrm{C}_{60}$ and AgBr. Surf. Sci. 1995, 338, 247 $-260$.

(23) Noy, A.; Frisbie, C. D.; Rozsnyai, L. F.; Wrighton, M. S.; Lieber, C. M. Chemical force microscopy: exploiting chemically-modified tips to quantify adhesion, friction and functional group distributions in molecular assemblies. J. Am. Chem. Soc. 1995, 7943-

7951.

(24) Miser, D. E.; Swinnea, J. S.; Steinfink, H. TEM Observations and Xray crystal-structure refinement of a twinned dolomite with a modulated microstructure. Am. Mineral. 1987, 72, 188-193.

(25) Pina, C. M.; Pimentel, C.; García-Merino, M. High resolution imaging of the dolomite (104) cleavage surface by atomic force microscopy. Surf. Sci. 2010, 604, 1877-1881.

(26) Pina, C. M.; Miranda, R.; Gnecco, E. Anisotropic surface coupling while sliding on dolomite and calcite crystals. Phys. Rev. B 2012, 85, No. 073402.

(27) Momma, K.; Izumi, F. VESTA 3 for three-dimensional visualization of crystal, volumetric and morphology data. J. Appl. Crystallogr. 2011, 44, 1272-1276.

(28) Maslen, E. N.; Streltsov, V. A.; Streltsova, N. R. X-ray study of the electron density in calcite, $\mathrm{CaCO}_{3}$. Acta Crystallogr., Sect. B: Struct. Sci. 1993, 49, 636-641.

(29) Graf, D. L. Crystallographic tables for the rhombohedral carbonates. Am. Mineral. 1961, 46, 1283-1316.

(30) Vilhena, J. G.; Pimentel, C.; Pedraz, P.; Luo, F.; Serena, P. A.; Pina, C. M.; Gnecco, E.; Pérez, R. Atomic-Scale Sliding Friction on Graphene in Water. ACS Nano 2016, 10, 4288-4293.

(31) Söngen, H.; Reischl, B.; Miyata, K.; Bechstein, R.; Raiteri, P.; Rohl, A. L.; Gale, J. D.; Fukuma, T.; Kühnle, A. Resolving point defects in the hydration structure of calcite (10.4) with three-dimensional atomic force microscopy. Phys. Rev. Lett. 2018, 120, No. 116101. 